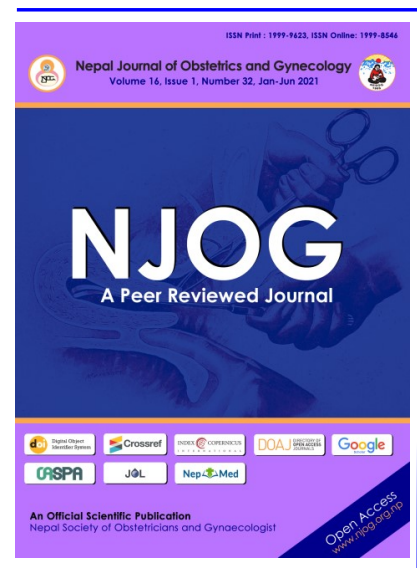

CORRESPONDENCE

Dr Rakina Bhansakarya

Department of Obstetrics and Gynecology

Nobel Medical College and Teaching Hospital, Biratnagar, Nepal.

Email:

rakina.bhansakarya@gmail. com; Phone: +9779819374896

Received: May 5, 2021

Accepted: May 20, 2021

\section{Citation:}

Bhansakarya R, Baral G, Subedi S, Ghimire S,

Shrestha P, Chaudhary AN. Obstetric profile during and before COVID 19 period pandemic at a teaching hospital in Eastern Nepal. Nep J Obstet Gynecol. 2021;16 (32):43-46. DOI: https:// doi.org/10.3126/ njog.v16i1.37516

\title{
Obstetric profile during and before COVID 19 period pan- demic at a teaching hospital in Eastern Nepal
}

\author{
Rakina Bhansakarya, Gehanath Baral, Shanti Subedi, Sita Ghimire, \\ Prajmi Shrestha, Amar Nath Chaudhary \\ Department of Obstetrics and Gynecology, Nobel Medical College and \\ Teaching Hospital, Biratnagar, Nepal
}

\section{ABSTRACT}

Aim: To compare fetomaternal outcomes among pregnant patients in COVID and non-COVID period in tertiary centre in eastern Nepal.

Methods: All women who delivered at Nobel Medical College Teaching Hospital during non-COVID period between April to June 2019 and COVID period between April to June 2020 were compared. Data were collected from medical records.

Results: Significant number of women had cesarean deliveries in COVID period $(36.5 \%$ vs $32.6 \%)$. There were no significant differences in period of gestation at the time of delivery, birth weight of baby, intrauterine fetal death and neonatal intensive care unit admission as well as no difference in obstetric outcomes, labor complications, maternal intensive care unit stay, near miss and peripartum hysterectomy.

Conclusion: There were more cesarean sections, vaginal birth after cesarean section and vaginal breech delivery in COVID period and no other significant differences in maternal and fetal outcomes during COVID period and NonCOVID period.

Keywords: COVID 19, intensive care unit, labor complications, near miss, neonatal intensive care unit

\section{INTRODUCTION}

WHO declared COVID 19 as pandemic from $11^{\text {th }}$ March 2020 and the lockdown started in Nepal from $24^{\text {th }}$ March 2020. Many pregnant patients could not get proper antenatal care and receive timely health facilities due to transportation ban during that time period. The hospitals had also stopped providing outpatients department services to the patients. Even with different modern technology like Telemedicine, it was still a great concern. ${ }^{1,2}$

The lockdown imposed by Nepalese government for COVID 19 has decreased the ANC visits and increased the fetomaternal complications rate. The objective of this study was to compare the incidence of maternal and fetal outcome before and during COVID pandemic.

\section{METHODS}

Medical records of all pregnant woman during the time frame of three months during COVID period $\left(1^{\text {st }}\right.$ April 2020 to $30^{\text {th }}$ June 2020) and non-COVID period ( $1^{\text {st }}$ April 2019 to $30^{\text {th }}$ June 2019) were reviewed. Variables under study were postdated pregnancy, preterm delivery, obstructed labor, severe preeclampsia, eclampsia, premature rupture of membrane (PROM), abruptio placentae, labor complications, mode of delivery, near miss cases, intensive care unit (ICU) stay, peripartum hysterectomy and fetal complications like low birth weight babies, intrauterine fetal death, stillbirth and Neonatal Intensive Care Unit (NICU) admission during COVID and non-COVID period.

A structured form in Excel was used 
to collect the data and it was exported to SPSS 21 (IBM, Armonk, NY, USA) for statistical analysis. Categorical data were analyzed using Chi Squared test and numerical data were analyzed using frequency, mean and standard deviation. Alfa-error was set at $\mathrm{p}<0.05$.

\section{RESULTS}

The number of deliveries during three months of Non-COVID period was $1673(60 \%)$ and three months in COVID period one year later in 2020 was 1087 (40\%), ie reduced by $35 \%$. Cesarean section and vaginal breech delivery were significantly higher during COVID period. [Table-1]

Table-1: Mode of delivery during and before COVID period

\begin{tabular}{lccc}
\hline & $\begin{array}{c}\text { Non COVID } \\
\text { period }\end{array}$ & $\begin{array}{c}\text { COVID } \\
\text { period }\end{array}$ & $\begin{array}{c}\mathrm{p}- \\
\text { value }\end{array}$ \\
\hline Total delivery & 1673 & 1087 & \\
Vaginal delivery & $1127(67.4 \%)$ & 690 & 0.035 \\
VBAC & $23(1.4 \%)$ & $17(1.6 \%)$ & 0.685 \\
Breech & $14(1.2 \%)$ & $19(2.8 \%)$ & 0.019 \\
Cesarean sec- & $546(32.6 \%)$ & 397 & 0.035 \\
tion & $65(11.9 \%)$ & $25(6.3 \%)$ & 0.004 \\
Elective & $481(88.1 \%)$ & $372(93.7 \%)$ & 0.004 \\
Emergency & & &
\end{tabular}

There was no difference by age and gravidity but more than $75 \%$ received labor care who were from within $100 \mathrm{~km}$ from the center. [Table-2]

Table-2: Sociodemographic characteristic of patient in Non-COVID and COVID period

\begin{tabular}{lll}
\hline & Non COVID period & COVID period \\
\hline Age (years) & $24.23 \pm 0.121$ & $24.77 \pm 0.158$ \\
Gravida & $1.78 \pm 0.026$ & $1.82 \pm 0.032$ \\
& Distance from study & site \\
$<100 \mathrm{~km}$ & $1277(76.3 \%)$ & $858(78.9 \%)$ \\
$100-200 \mathrm{~km}$ & $326(19.5 \%)$ & $194(17.8 \%)$ \\
$>200 \mathrm{~km}+$ & $46(2.7 \%)$ & $33(3 \%)$ \\
Hilly region & $24(1.4 \%)$ & $2(0.2 \%)$ \\
India & 240 \\
\hline
\end{tabular}

The major indications of Cesarean section in COVID and Non COVID period are tabulated and the major indication for Cesarean section was fetal distress in both the time periods. There were significantly more number of Cesarean section done for fetal distress and non-progress of labor/ obstructed labor in COVID period. However, in Non-COVID period, there were significantly more cesarean section done for failed induction and cephalopelvic disproportion. [Table3]
Table-3: Primary indication of Cesarean section in Non-COVID and COVID period

\begin{tabular}{lccc}
\hline Indications & $\begin{array}{c}\text { Non COVID } \\
\text { period } \\
(\mathrm{n}=546)\end{array}$ & $\begin{array}{c}\text { COVID } \\
\text { period } \\
(\mathrm{n}=397)\end{array}$ & $\begin{array}{c}\mathrm{p}- \\
\text { value }\end{array}$ \\
\hline Previous LSCS & $159(28.9 \%)$ & $127(32 \%)$ & 0.314 \\
Fetal distress & $167(30.8 \%)$ & $142(35.8 \%)$ & 0.043 \\
Failed induction & $88(16.1 \%)$ & $44(11.1 \%)$ & 0.028 \\
$\begin{array}{l}\text { Malpresentation } \\
\text { Cephalopelvic }\end{array}$ & $57(10.45 \%)$ & $37(9 \%)$ & 0.0932 \\
disproportion & $47(8.6 \%)$ & $5(1.3 \%)$ & 0.001 \\
$\begin{array}{l}\text { Non-progress/ } \\
\text { obstructed labor }\end{array}$ & $13(2.4 \%)$ & $25(3.5 \%)$ & 0.001 \\
$\begin{array}{l}\text { Placenta previa } \\
\text { Cord prolapse }\end{array}$ & $9(1.6 \%)$ & $13(3.3 \%)$ & 0.102 \\
Others & $2(0.4 \%)$ & 0 & - \\
\hline
\end{tabular}

There were more extreme preterm births in COVID period $(1.9 \%$ vs $1 \%$; p-value $<0.05)$ but no any significant differences in terms of early and late preterm births or in postdated pregnancies between COVID and Non-COVID period. [Table-4]

Table-4: Period of gestation in in Non-COVID and COVID period

\begin{tabular}{llll}
\hline $\begin{array}{l}\text { Weeks of } \\
\text { gestation }\end{array}$ & $\begin{array}{l}\text { Non-COVID } \\
\text { period }(\mathrm{n}=1673)\end{array}$ & $\begin{array}{l}\text { COVID period } \\
(\mathrm{n}=1087)\end{array}$ & p-value \\
\hline$<28$ & $17(1 \%)$ & $21(1.9 \%)$ & 0.04 \\
$28-36$ & $228(13.6 \%)$ & $141(12.97 \%)$ & 0.62 \\
$37-39$ & $821(49.1 \%)$ & $496(45.6 \%)$ & 0.07 \\
$\geq 40$ & $503(30.1 \%)$ & $357(32.8 \%)$ & 0.124 \\
$\geq 42$ & $51(3 \%)$ & $21(1.9 \%)$ & 0.07 \\
Unknown & $53(3.2 \%)$ & $51(4.7 \%)$ & 0.04 \\
\hline
\end{tabular}

There were no significant differences in terms of birth weight, neonatal intensive care unit admission, intrauterine fetal death and stillbirth in babies delivered during Non-COVID and COVID period. [Table-5]

Table-5: Fetal outcome and baby weight in NonCOVID and COVID period

\begin{tabular}{|c|c|c|c|c|}
\hline \multicolumn{2}{|c|}{ Parameters } & $\begin{array}{c}\text { Non-COVID } \\
(n=1673)\end{array}$ & $\begin{array}{l}\text { COVID } \\
(n=1087)\end{array}$ & $\begin{array}{c}\mathrm{p}- \\
\text { value }\end{array}$ \\
\hline \multirow{6}{*}{ 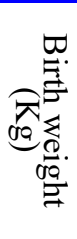 } & Mean & $2.22 \pm 0.45$ & $2.27 \pm 0.56$ & - \\
\hline & $<1$ & $9(0.6 \%)$ & $5(0.5 \%)$ & 0.778 \\
\hline & $1-1.5$ & $40(2.4 \%)$ & $21(2 \%)$ & 0.423 \\
\hline & $1.5-2.5$ & $406(24.8 \%)$ & $263(25.2 \%)$ & 0.965 \\
\hline & $2.5-4$ & $1165(71.3 \%)$ & $746(71.5 \%)$ & 0.576 \\
\hline & $>4$ & $15(0.9 \%)$ & $9(0.9 \%)$ & 0.85 \\
\hline \multirow{5}{*}{ ᄋ } & $\begin{array}{l}\text { NICU } \\
\text { admission }\end{array}$ & $171(10.2 \%)$ & $130(12 \%)$ & 0.152 \\
\hline & IUFD & $46(2.7 \%)$ & $44(4 \%)$ & 0.06 \\
\hline & Stillbirth & $9(0.5 \%)$ & $3(0.3 \%)$ & 0.307 \\
\hline & Twins & $28(1.7 \%)$ & $23(2.1 \%)$ & 0.468 \\
\hline & Triplets & 0 & 1 & - \\
\hline
\end{tabular}


There were more patients with abruptio placentae, placenta previa and prelabor rupture of membrane in COVID period; but at the same time, infection, preeclampsia, eclampsia, anemia requiring blood transfusion, oligohydramnios and labor complications like $3^{\text {rd }}$ or $4^{\text {th }}$ degree perineal tear and retained placenta were more during non-COVID period. There were thirty-nine cases of near miss pregnancies, out of which, twenty-five were in non COVID period and fourteen in COVID period. There were twenty one cases of postpartum hemorrhage overall and ten cases of peripartum hysterectomy overall, six in COVID period and four in non COVID period. [Table-6]

Table-6: Maternal complications in Non-COVID and COVID period

\begin{tabular}{|c|c|c|c|c|}
\hline \multicolumn{2}{|c|}{ Antenatal and labor complications } & Non-COVID & COVID & p-value \\
\hline \multirow{11}{*}{ 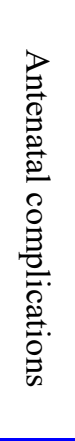 } & Infection & $18(1.1 \%)$ & $7(0.6 \%)$ & 0.242 \\
\hline & Preeclampsia & $81(4.8 \%)$ & $38(3.5 \%)$ & 0.08 \\
\hline & Eclampsia & $21(1.3 \%)$ & $9(0.8 \%)$ & 0.29 \\
\hline & Anemia (blood transfusion) & $12(0.7 \%)$ & $7(0.6 \%)$ & 0.8 \\
\hline & Oligohydramnios & $57(3.4 \%)$ & $26(2.4 \%)$ & 0.127 \\
\hline & Abruptio placentae & $12(0.7 \%)$ & $11(1 \%)$ & 0.405 \\
\hline & Placenta previa & $12(0.7 \%)$ & $13(1.2 \%)$ & 0.195 \\
\hline & Prelabor rupture of membrane & $174(10.4 \%)$ & $119(10.9 \%)$ & 0.648 \\
\hline & Heart disease & $3(0.2 \%)$ & $5(0.4 \%)$ & - \\
\hline & Respiratory complications & $9(0.5 \%)$ & $2(0.2 \%)$ & - \\
\hline & Acute kidney injury & $6(0.4 \%)$ & $3(0.3 \%)$ & - \\
\hline \multirow{6}{*}{ 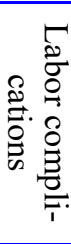 } & Perineal tear (3rd or 4th degree) & $3(0.2 \%)$ & $1(0.1 \%)$ & - \\
\hline & Cervical tear & $5(0.3 \%)$ & 0 & - \\
\hline & Retained placenta & $5(0.3 \%)$ & $1(0.1 \%)$ & - \\
\hline & Maternal near miss & $25(1.5 \%)$ & $14(1.3 \%)$ & 0.654 \\
\hline & Ruptured uterus & $1(0.1 \%)$ & $2(0.2 \%)$ & - \\
\hline & Peripartum Hysterectomy & $4(0.2 \%)$ & $6(0.6 \%)$ & 0.206 \\
\hline
\end{tabular}

\section{DISCUSSION}

With regards to perinatal outcome, it was noticed that there were more number of IUFD in COVID period and more NICU admission as well. However studies have shown that there could be vertical transmission of virus from mother to baby in a study done by Chen $\mathrm{H}$ et al. ${ }^{3}$

There were more extreme preterm $(<28$ weeks) deliveries during COVID period $(\mathrm{p}=0.04)$. This finding corresponds with the finding of Liao et al where there is more preterm deliveries in COVID positive pregnant patients. ${ }^{4}$

There was no significant difference with respect to birth weight. The studies have noted that restriction to intrauterine growth in COVID 19 positive patients can occur if the mother is symptomatic and have hypoxia; but since none of our patients were symptomatic nor were tested for COVID 19 no positive or negative association could be made with intrauterine growth restriction.,

The transportation was a great hurdle in the time period leading to delay for pregnant women to reach hospital in time for delivery. There were more deliveries of pregnant woman who lived in or near Biratnagar $(<100 \mathrm{~km})$ and there was decrease in inflow of patient from Indian villages along In-
do-Nepal border. The studies by Alsharaydeh ${ }^{7}$ and Ehiri et $\mathrm{al}^{8}$ also emphasized on the fact that adverse pregnancy and childbirth outcome in low and middle income countries are due to delay in reaching a health facility for emergency obstetric care.

There were more VBAC and vaginal breech deliveries in COVID period as they might have arrived hospital in late active phase of labor. This findings makes us recognize that during COVID period, pregnant patients do not seek early obstetric care unless there is dire emergency. ${ }^{9-11}$ Similarly, there were more emergency cesarean deliveries and protracted labor in COVID period.

Maternal complications were also compared but interestingly there were more complications noted in non COVID period than COVID period i.e. there were more infection, preeclampsia, eclampsia, anemia, premature rupture of membrane in non -COVID period. Few exceptions like placenta previa, abruptio placentae were found more in COVID period. The difference could be the travel ban itself as referral from distant places could not reach our hospital and this could have been reason for less number of complicated patients getting admitted during COVID period. Those patients with complications must have been managed in the 
community hospital and we do not have data regarding that.

ICU stay, maternal mortality, near miss, the number of ruptured uterus and peripartum hysterectomy gives us a glimpse of the overall maternal wellbeing and labor conduct in a hospital setting and these parameters were also compared. But in contrast, ICU stay was more in non COVID period. While analyzing the cases, it was found that the reason for ICU admission in non-COVID period was referral from other hospital for non-obstetric related medical conditions. The studies have shown that pregnancy modulates the immune system. Progesterone inhibits Th1 proinflammatory pathway and this modulated immune system could be one of the factors that have protected pregnant women from cytokine storm of COVID 19 virus. ${ }^{12,13}$ Since, we haven't sent PCR test for COVID virus for our patients so any association cannot be made with the virus and morbidity of the patient.

In studies done by Tassis et $\mathrm{al}^{14}$ and Ochiai et $\mathrm{al}^{15}$ in Japan, they had implemented universal screening for COVID 19 virus in asymptomatic obstetric patients and if this can be done in further studies then relation of this virus with the obstetric outcome could be easily made. Limitation of this study was the lack of PCR test for SARS COV2 during the defined study period in order to associate pregnancy outcome with COVID status.

\section{CONCLUSIONS}

There were more cesarean sections, vaginal birth after cesarean section and vaginal breech delivery in COVID period imposing the fact that there was delay in seeking obstetric care by pregnant women. However, there were no other significant differences in maternal and fetal outcomes during COVID period and Non-COVID period.

\section{REFERENCES}

1. Adamson D, Rosenwaks Z, Zephne Van Der S, Ivonne Diaz Y. Reproductve health paradigms in tmes of COVID-19. Int J Gynecol Obs. 2020;150 (2):139-40.

2. Fryer K, Delgado A, Foti T, Reid CN, Marshall J. Implementation of obstetric telehealth during COVID-19 and beyond. Matern Child Health J. 2020;24:1104-10.

3. Chen H, Guo J, Wang C, Luo F, Yu X, Zhang W, et al. Clinical characteristics and intrauterine vertical transmission potential of COVID-19 infection in nine pregnant women: a retrospective review of medical records. Lancet. 2020;395 (10226):809-15.

4. Liao J, He X, Gong Q, Yang L, Zhou C, Li J. Analysis of vaginal delivery outcomes among pregnant women in Wuhan, China during the COVID-19 pandemic. Int $J$ Gynecol Obstet. 2020;150(1):53-7.
5. Deprest J, Choolani M, Chervenak F, Farmer D, Lagrou K, Lopriore E, et al. Fetal Diagnosis and Therapy during the COVID-19 Pandemic: Guidance on Behalf of the International Fetal Medicine and Surgery Society. Fetal Diagn Ther. 2020;47(9):689-98.

6. Ream M, Ray AM, Chandra R, Chikaraishi DM. Early fetal hypoxia leads to growth restriction and myocardial thinning. Am J Physiol - Regul Integr Comp Physiol. 2008;295(3):58395.

7. Alsharaydeh I, Rawashdeh H, Saadeh N, Obeidat B, Obeidat N. Challenges and solutions for maternity and gynecology services during the COVID-19 crisis in Jordan. Int J Gynecol Obstet. 2020;150(2):159-62.

8. Ehiri J, Alaofè H, Asaolu I, Chebet J, Esu E, Meremikwu M. Emergency transportation interventions for reducing adverse pregnancy outcomes in low- and middle-income countries: a systematic review protocol. Syst Rev.2018;7 (65). DOI:10.1186/s13643-018-0729-2

9. Pacagnella R, Cecatti J, Osis M, Souza J. The role of delays in severe maternal morbidity and mortality: expanding the conceptual framework. Reprod Heal Matters. 2012;20(39):15563.

10.Nwafor JI, Aniukwu JK, Anozie BO, Ikeotuonye AC, Okedo-Alex IN. Pregnant women's knowledge and practice of preventive measures against COVID-19 in a low-resource African setting. Int J Gynecol Obstet. 2020;150 (1):121-3.

11.Obeidat N, Saadeh R, Obeidat M, Khasawneh W, Khader Y, Alfaqih M. Perceptions of obstetricians and pediatricians about the risk of COVID-19 for pregnant women and newborns. Int J Gynecol Obstet. 2020;150(3):306-11.

12.Farida E, Rana M, Nader $H$, Mohamed E, Nourhan F, Shahd M, et al. A systematc scoping review of COVID-19 during pregnancy and childbirth. Int J Gynecol Obs. 2020;150:47-52.

13.Khan S, Peng L, Siddique R, Nabi G, Nawsherwan, Xue M, et al. Impact of COVID-19 infection on pregnancy outcomes and the risk of maternal-to-neonatal intrapartum transmission of COVID-19 during natural birth. Infect Control Hosp Epidemiol. 2020;41(6):748-50.

14.Tassis B, Lunghi G, Frattaruolo M, Ruggerio $\mathrm{M}$, Somigliana E, Ferrazzi E. Effectiveness of a COVID-19 screening questonnaire for pregnant women at admission to an obstetric unit in Milan. Int J Gynecol Obstet. 2020;150(1):124-6.

15.Ochiai D, Kasuga Y, Iida M, Ikenoue S, Tanaka M. Universal screening for SARS-CoV-2 in asymptomatc obstetric patents in Tokyo, Japan. Int J Gynecol Obs. 2020;150(2):268-9. 